\title{
(C) OPEN ACCESS \\ Liver sampling: a vital window into HBV pathogenesis on the path to functional cure
}

\author{
Upkar S Gill, ${ }^{1}$ Laura J Pallett, ${ }^{2}$ Patrick T F Kennedy, ${ }^{1}$ Mala K Maini ${ }^{2}$
}

'Department of Hepatology, Centre for Immunobiology, Blizard Institute, Barts and the London School of Medicine and Dentistry, Queen Mary University of London, London, UK

${ }^{2}$ Division of Infection and Immunity, UCL, London, UK

Correspondence to Dr Upkar S Gill, Department of Hepatology, Blizard Institute, Barts and the London School of Medicine and Dentistry, QMUL, London, UK; u.gill@qmul.ac. uk and Professor Mala K Maini, Division of Infection and Immunity, UCL, London, WC1E 6JF, UK; m.maini@ucl.ac.uk

Received 17 July 2017 Revised 29 November 2017 Accepted 7 December 2017 Published Online First 13 January 2018
Check for updates

To cite: Gill US, Pallett LJ, Kennedy PTF, et al. Gut 2018:67:767-775

\section{ABSTRACT}

In order to optimally refine the multiple emerging drug targets for hepatitis B virus (HBV), it is vital to evaluate virological and immunological changes at the site of infection. Traditionally liver biopsy has been the mainstay of HBV disease assessment, but with the emergence of non-invasive markers of liver fibrosis, there has been a move away from tissue sampling. Here we argue that liver biopsy remains an important tool, not only for the clinical assessment of HBV but also for research progress and evaluation of novel agents. The importance of liver sampling has been underscored by recent findings of specialised subsets of tissueresident immune subsets capable of efficient pathogen surveillance, compartmentalised in the liver and not sampled in the blood. Importantly, the assessment of virological parameters, such as cccDNA quantitation, also requires access to liver tissue. We discuss strategies to maximise information obtained from the site of infection and disease pathology. Fine needle aspirates of the liver may allow longitudinal sampling of the local virus/ host landscape. The careful utilisation of liver tissue and aspirates in conjunction with blood will provide critical information in the assessment of new therapeutics for the functional cure of HBV.

\section{THE BACKDROP}

Viral hepatitis remains the seventh most common cause of death worldwide, with mortality increasing sharply in the last decade to levels on the scale of HIV, tuberculosis or malaria. ${ }^{1}$ The dramatic recent progress in hepatitis $C$ treatment means that this infection can now be cured with short courses of direct-acting antivirals, shifting the impetus to better case-finding and enhancing accessibility to these effective but expensive drugs. By contrast, hepatitis $\mathrm{B}$ can still only be cured in a tiny minority of the estimated 240 million people chronically infected with this virus. Reducing new infections by vaccination and other preventative measures remains of paramount importance and in this regard, it is welcome news that the UK joined other EU nations with universal hepatitis B virus (HBV) vaccination of all neonates in 2017. For those already infected with HBV, there is the prospect of better treatments on the horizon, with efforts and expectations in academia and industry being dramatically intensified in response to progress in the fields of hepatitis $\mathrm{C}$ virus (HCV) infection and cancer. There is now a worldwide call for wider access to existing suppressive therapies, to be followed by attempts to achieve the state of functional cure seen following natural resolution of acute infection, with minimal residual virus kept under long-term immune control without the need for ongoing antiviral drugs. ${ }^{23}$

$\mathrm{HBV}$ is an hepatotropic virus, so the site of viral replication and disease pathogenesis is within the liver. Traditionally, a mainstay of management has therefore included assessment of liver histology using tissue obtained by a needle core biopsy. This remains the most accurate way of definitively assessing the degree of liver fibrosis for initial HBV disease staging and of ruling out other causes of liver disease. There is a strong case for the continued assessment of liver histology in combination with serological markers for treatment decisions, particularly in ambiguous cases. In addition, their use may instigate other clinical investigations (eg, gastroscopy to exclude portal hypertension), in cases where advanced liver disease is detected. Liver biopsy is, however, no longer the standard of care in a number of clinics due to the advent of non-invasive methods of fibrosis assessment. ${ }^{45}$ The use of transient elastography (TE) and serum markers to assess fibrosis, along with indirect assessment of liver inflammation/damage by serum transaminases and quantitation of circulating hepatitis $\mathrm{B}$ viral load and antigens is increasingly being regarded as an adequate alternative. This is reflected in recent updates to national and international clinical practice guidelines in which TE is recommended as the first-line modality for disease assessment, with liver biopsy reserved for indeterminate cases (figure 1). ${ }^{6-13}$ The move away from liver biopsies in routine HBV assessment is likely influenced by the fact that their use in HCV disease management has been rendered almost redundant. However, the place of liver biopsy in the management of chronic hepatitis $\mathrm{B}$ infection $(\mathrm{CHB})$ is currently a subject of much debate.

TE, using FibroScan, allows rapid assessment of liver stiffness by employing a shear-wave to measure vibration-velocity, a technique previously used in the food industry to gauge the maturity of cheese. ${ }^{14}$ TE, and serum-based markers such as the enhanced liver fibrosis test (ELF) $)^{15} 16$ have some advantages (table 1) including better patient acceptability and suitability for longitudinal assessment. However, their major disadvantage is limited validation and lower diagnostic accuracy in $\mathrm{HBV}$, particularly with coincident inflammation or steatosis. ${ }^{517} 18$ Liver biopsy remains the 'gold standard' for the definitive assessment of HBV disease stage (table 1) and the availability of different techniques (Box) allows selection of the most appropriate for each case in order to minimise the small overall risk. Liver biopsy, as discussed below, is subject to sampling error and 


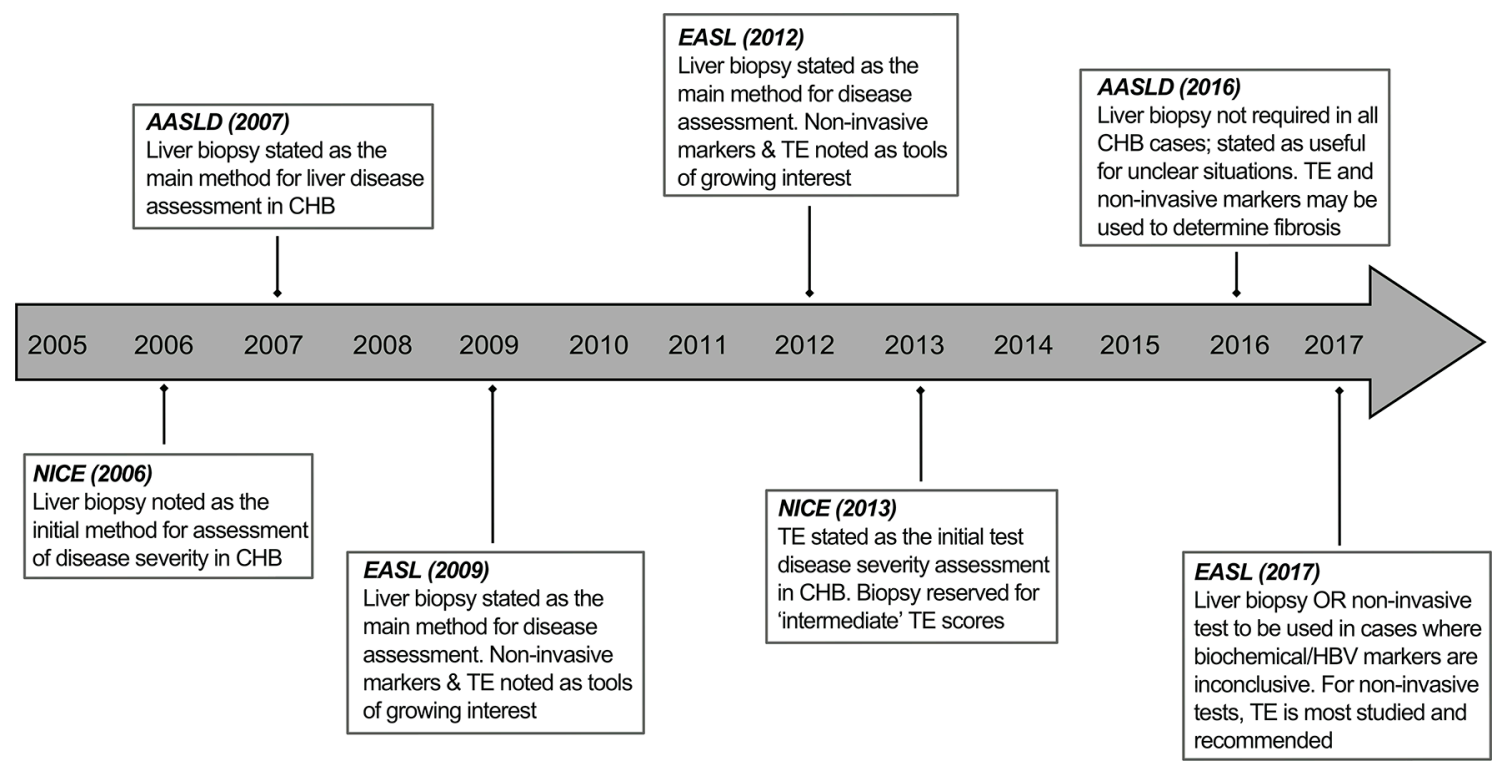

Figure 1 Historical progression of the modality of liver disease assessment as outlined in national and international clinical practice guidelines for hepatitis B virus. CHB, chronic hepatitis B; NICE, National Institute for Health and Care Excellence; TE, transient elastography.

should, ideally, be complemented by non-invasive assessments conducted in parallel and then used for follow-up for the clinical management of HBV.

In this article, we argue that liver biopsy remains an important tool in the majority of patients with HBV infection, for clinical disease assessment and for research progress and evaluation of novel agents (table 1). Even in cases where the information gleaned may not directly alter patient management, it is pivotal for the optimisation of future therapeutics, and an argument can therefore be made to seek ethical approval for such sampling. We review new findings on compartmentalisation within the liver, including a population of tissue-resident $\mathrm{T}$ cells capable of acting as local specialists in immune defence. On the basis of the many crucial aspects that cannot be assessed in the blood, we propose that liver biopsy should remain part of disease assessment in $\mathrm{CHB}$ and be prioritised in the evaluation of new strategies for functional cure of HBV.

\section{WHAT WE CAN SAMPLE IN THE BLOOD Immune parameters}

Most studies of HBV immune responses in humans have relied solely on blood sampling; many clear-cut changes have been detectable and useful insights into disease pathogenesis have been made. In a few studies, responses studied thoroughly in the periphery have been compared with those within intrahepatic lymphocytes by paired sampling of the liver in a small subset of donors. ${ }^{19-27}$ Until recently, such comparisons had generally validated blood monitoring, showing that findings made from the periphery were representative of their intrahepatic counterparts, with the same responses and features simply being present in a more exaggerated form in the liver (figures 2 and 3). HBV-specific CD8 T cells, critical for antiviral control, were found to be present at higher frequency in the liver than the blood but retained the same inverse correlation between frequency and viral load in both sites. ${ }^{19} 24$ It has been possible to define important

\begin{tabular}{|c|c|c|}
\hline & Liver biopsy & TE and non-invasive markers of fibrosis \\
\hline Advantages & $\begin{array}{l}\text { Definitive histological diagnosis* } \\
\text { Allows exclusion of other liver diseases* } \\
\text { Accurate fibrosis stage* } \\
\text { Additional assessment of necroinflammatory reaction and steatosis* } \\
\text { Validated score for HBV* } \\
\text { Helpful for delineation in intermediate disease* } \\
\text { Surplus tissue and slides stored for retrospective analysis }{ }^{*} \dagger \\
\text { Tissue availability for routine HBV virological assessment }\left(\mathrm{HBsAg} \text { staining) }{ }^{*} \dagger\right. \\
\text { Tissue availability for state-of-the-art virology (eg, cccDNA, integrated DNA) }{ }^{*} \\
\text { Tissue availability for state-of-the-art immunology research (eg, resident lymphocytes, HBV- } \\
\text { specific T cells) } \dagger\end{array}$ & $\begin{array}{l}\text { Minimal risk* } \\
\text { Easy to perform* } \\
\text { Lower cost per test* } \\
\text { Painless, good patient acceptability } \\
\text { Immediate results available at 'point of care' } \ddagger^{*} \\
\text { Easily repeated, allows longitudinal assessment* }\end{array}$ \\
\hline Disadvantages & $\begin{array}{l}\text { Invasive, bleeding risk }(0.01 \% \text { mortality })^{*} \\
\text { Pain-related morbidity, variable patient acceptability* } \\
\text { Sampling error* } \\
\text { - Contraindicated in certain cases* } \\
\text { - High cost per test* }\end{array}$ & $\begin{array}{l}\text { Costly equipment } \ddagger^{*} \\
\text { Technical expertise required } \ddagger^{*} \\
\text { Unreliable in obese patients } \ddagger^{*} \\
\text { Skewed results with deranged LFTs } \ddagger^{*} \\
\text { Optimal cut-off levels not validated in HBV* }\end{array}$ \\
\hline
\end{tabular}

*Relevant for clinical purposes.

†Relevant for research purposes.

‡Relevant to TE only.

ccCDNA, covalently closed circular DNA; HBV, hepatitis B virus; $H B s A g$, hepatitis B surface antigen; LFT, liver function test; $T E$, transient elastography . 


\section{Box Types of liver biopsy}

- Percutaneous biopsy:

- Palpation/percussion guided or image-guided; transthoracic approach most common, subcostal approach may be used*

- Transvenous biopsy:

- Transjugular/transfemoral approach. Required in patients with clotting abnormalities and ascites and for indications where free/wedge hepatic vein pressure measurements are required.

- Laparoscopic/surgical biopsy:

- May be performed at time of surgical intervention. Liver can be directly visualised thus tissue yield is good, but general anaesthesia is required.

- Coaxial biopsy:

- Needle puncture device through which smaller needle biopsies are performed. Multiple passes through this approach can be performed.

*Percutaneous biopsies can be performed with core aspiration needles; Menghini, Jamshidi or Klatskin. Usually performed with 16G needle which provides better cores, $18 \mathrm{G}$ needles may be used which may be better accepted by patients, but cores may be more fragmented. Sheath cutting needles may also be used (Tru-cut), usually smaller gauge, but sample may be less fragmented.

mechanisms constraining these antiviral responses within the blood, such as their expression of the coinhibitory molecule programmed cell death protein 1 (PD-1), the death receptor, TNF-related apoptosis-inducing ligand receptor 2 (TRAIL-R2) and the oxidative stress ligand MHC class I polypeptide-related sequence A (MICA), although these changes became far more evident when examining their intrahepatic counterparts. ${ }^{24} 262829$

Similarly, we were able to detect an expansion of granulocytic myeloid-derived suppressor cells correlating with disease activity in the circulation of patients with $\mathrm{CHB}$, although in the liver this population was further expanded, expressing a more immunoregulatory phenotype (increased arginase I and degranulation, marked by increased surface expression of CD63). ${ }^{30}$ Other immune responses, such as B cells, are not enriched in the liver and, along with antibody responses, are easily studied in the periphery ${ }^{31}$; however, their further evaluation in the liver remains important in light of work suggesting they can play local pathogenic roles in $\mathrm{HBV}^{32}$ Crucially, as discussed below, it has now become evident that some specialised immune populations are completely compartmentalised in the liver, making the blood only one component of an adequate assessment of HBV immunity.

\section{Virological parameters: emerging surrogates of covalently closed circular DNA in the periphery}

The study of covalently closed circular DNA (cccDNA), the episomal viral genome of HBV within hepatocyte nuclei, remains of critical importance as extensive efforts are made to develop therapeutic approaches to degrade or silence it. A major barrier to progress in the field has been the inability to accurately measure cccDNA in blood and assays for its determination in the periphery are likely to face many hurdles. ${ }^{33}$ While serum HBV DNA and hepatitis B envelope antigen ( $\mathrm{HBeAg}$ ) status remain the foundation of virological assessment in today's clinic, they provide limited information on cccDNA. ${ }^{34-36}$ This has led to a rigorous search for surrogates of cccDNA in the periphery. ${ }^{37}$ Progress in this sphere will be dependent on access to liver tissue to validate the utility of any putative new marker. In recent

Figure 2 Schematic of A) peripheral and B) intrahepatic lymphocyte populations depicting examples that can be sampled from both sites but have an exagerated phenotype in the liver and others that are unique to the liver. 
years, quantitative $\mathrm{HBsAg}$ (qHBsAg), which is readily measured in the serum, has been proposed as a robust measure of cccDNA transcription. However, recent findings suggest that in patients with $\mathrm{HBeAg}$-negative disease and those who have received longterm nucleos(t)ide analogues (NAs), integrated DNA, rather than cccDNA, is a major source of circulating HBsAg. ${ }^{3839}$ In addition, the quantity of HBsAg measured in the serum as free HBsAg has the possibility of being confounded by the presence of immune complexes with coexisting anti-HBs, or the emergence of pre-S/S variants preventing HBsAg release from hepatocytes, thus giving an unreliable measurement of total HBsAg. ${ }^{40}$ Future assays will aim to distinguish the small, medium and large constituent proteins of HBsAg, as well as that derived from cccDNA versus integrated DNA.

More recently, hepatitis B core-related antigen (HBcrAg) has emerged as a potentially more accurate surrogate for cccDNA than qHBsAg. Assays for 'core-related antigen' measure denatured HBeAg, HBcAg and the pre-core protein (aa28 to aa15) ${ }^{42}$ using a chemiluminescent enzyme immunoassay and reflect the sum of complete virions (with rcDNA or viral RNA), empty virions and secreted HBeAg. When HBV DNA becomes undetectable on NA therapy, HBcrAg should better reflect the quantity and transcriptional activity of cccDNA than qHBsAg, since it is unlikely to be produced by integrated DNA. In line with this, studies have shown that HBcrAg correlates with intrahepatic cccDNA both in treatment naïve patients ${ }^{43}$ and in those treated with NAs, ${ }^{44}$ although these findings have yet to be validated across all patient groups and genotypes.

HBV RNA can also be measured in the serum. It is packaged within nucleocapsids and both full-length and truncated RNA forms can circulate in patients. ${ }^{45}$ Prior to $\mathrm{HBeAg}$ seroconversion, HBV RNA levels are thought to fall and thus can predict HBeAg seroconversion. ${ }^{46}$ Levels of HBV RNA are also presumed to reflect intrahepatic cccDNA transcription. During NA therapy, pregenomic RNA from ongoing cccDNA transcription can no longer be reverse transcribed and instead accumulates and is encapsidated; secreted levels may serve as a predictor of viral rebound. ${ }^{47}$ However, no commercial assays are available for detecting HBV RNA levels and thus its utility as a surrogate for intrahepatic cccDNA remains unclear at this juncture.

\section{WHAT WE ARE MISSING IN THE BLOOD Histology}

Histology provides a more detailed assessment of the liver, reflecting cumulative damage over time in addition to ongoing inflammation. A recent meta-analysis of 683 patients has shown that even with slight increases in alanine aminotransferase (ALT), a substantial number of patients (up to 50\%) have significant fibrosis. ${ }^{48}$ Moreover, in patients with normal serum ALT and levels of HBV DNA between 2000 and $20000 \mathrm{IU} / \mathrm{mL}$ (so-called grey-zone patients), significant levels of fibrosis have been reported. ${ }^{49}$ We have previously shown that patients considered 'immune tolerant' (HBeAg+chronicinfection) had levels of fibrosis similar to those found in patients labelled immune active (HBeAg \pm chronichepatitis), notwithstanding differences in biochemical and virological parameters. ${ }^{50}$

Validated histological scoring systems are used in HBV; Ishak, Knodell and METAVIR being routinely used to assess disease activity. ${ }^{51}$ However, the potential for sampling error and interobserver/intraobserver variability may lead to inaccuracy of fibrosis staging from liver biopsy alone. New methods of tissue image analysis to detect collagen proportionate area ${ }^{52}$ and collagen scoring by novel tools such as second harmonic imaging ${ }^{53}$ will reduce subjectivity. A liver biopsy can additionally be used to identify the coexistence of other diseases; in particular coincident steatosis and non-alcoholic steatohepatitis, an increasingly common comorbidity, would be indistinguishable from HBV-related liver inflammation without a biopsy. ${ }^{54}$ The ability to score interface hepatitis, confluent necrosis, portal inflammation, focal lytic necrosis, apoptosis and focal inflammation, which constitute the histological activity index/necroinflammatory index, is unique to histological assessment of liver tissue. ${ }^{55}$

Beyond diagnostic evaluation, additional immunohistochemical staining can be undertaken, providing novel insights into HBV immunopathogenesis. Combining histochemical analysis of liver injury with specialised stains of paraffin-embedded sections for immune cell distribution can provide valuable insights into HBV pathogenesis. For example, interleukin (IL)-17-producing CD4 $\mathrm{T}$ cells were seen to accumulate in the lobular and portal areas of livers with $\mathrm{HBV}$-related injury, suggesting a role in disease pathogenesis. ${ }^{56}$ Localisation of natural killer (NK) cells in areas of hepatic necrosis implicated them in HBV-related liver damage $^{57}$; NK cells expressing the death ligand TRAIL, and hepatocytes expressing the death-inducing receptor TRAIL-R2, were both increased on histological staining of HBV-infected livers, pointing to a pathogenic role for this pathway. ${ }^{21} \mathrm{Much}$ remains to be learnt from more in-depth histology, to assess the topological relationship between viral particles, immune infiltrates and disease pathology using newly available multiparameter analysis, as discussed below.

\section{Immunological features of the liver}

The liver has an immunological composition which is distinct from blood or other lymphoid and non-lymphoid organs. Its inherent cellular composition is strikingly different, and even when circulating cell types pass through the liver they may be differentially shaped by the local milieu of cytokines, nutrients and hypoxia; these influences are likely to be exaggerated by the sluggish blood flow through the narrow-lumen vascular bed of the sinusoids. ${ }^{58}$ In addition to the parenchymal cells (hepatocytes) that HBV replicates within, the liver contains unique non-parenchymal cell types including specialised scavengers/ antigen-presenting cells such as liver sinusoidal endothelial cells and Kupffer cells (liver-specific macrophages) that can influence neighbouring lymphocytes. ${ }^{58} 59$ Although Kupffer cells are the largest macrophage population in humans, they have been difficult to study due to lack of adequate markers to distinguish them from liver-infiltrating monocytes. ${ }^{60}$ They contribute to the tolerogenic environment provided by the liver, by producing immunosuppressive cytokines such as IL-10 and transforming growth factor- $\beta$ (TGF- $\beta){ }^{61}$

The intrahepatic lymphocyte population is very different from blood (figure 3); for example, the liver is selectively enriched for CD8 rather than CD4 $\mathrm{T}$ cells, a reversal of the situation in the blood. While classical Tregs (CD25+FoxP3 +CD4+) have been identified in both blood and liver of patients with $\mathrm{CHB},{ }^{62-65}$ an atypical regulatory population of CD25-FoxP3 +CD $4+\mathrm{T}$ cells has been found to be unique to the liver. ${ }^{66}$ The large population of CD8 T cells in the liver is dominated by memory subsets, with significantly less naïve CD8 T cells than blood. ${ }^{67} \mathrm{NK}$ cells are much more prevalent in the liver than other peripheral tissues (with the exception of the uterus), ${ }^{68}$ accounting for up to $40 \%$ of all intrahepatic lymphocytes. ${ }^{57} 69$ More recently, it has been recognised that mucosal-associated invariant $\mathrm{T}$ cells are another innate-like cell that preferentially accumulate within the liver, at higher frequencies than either the blood or gut. ${ }^{70}$ In addition 


\section{blood liver}

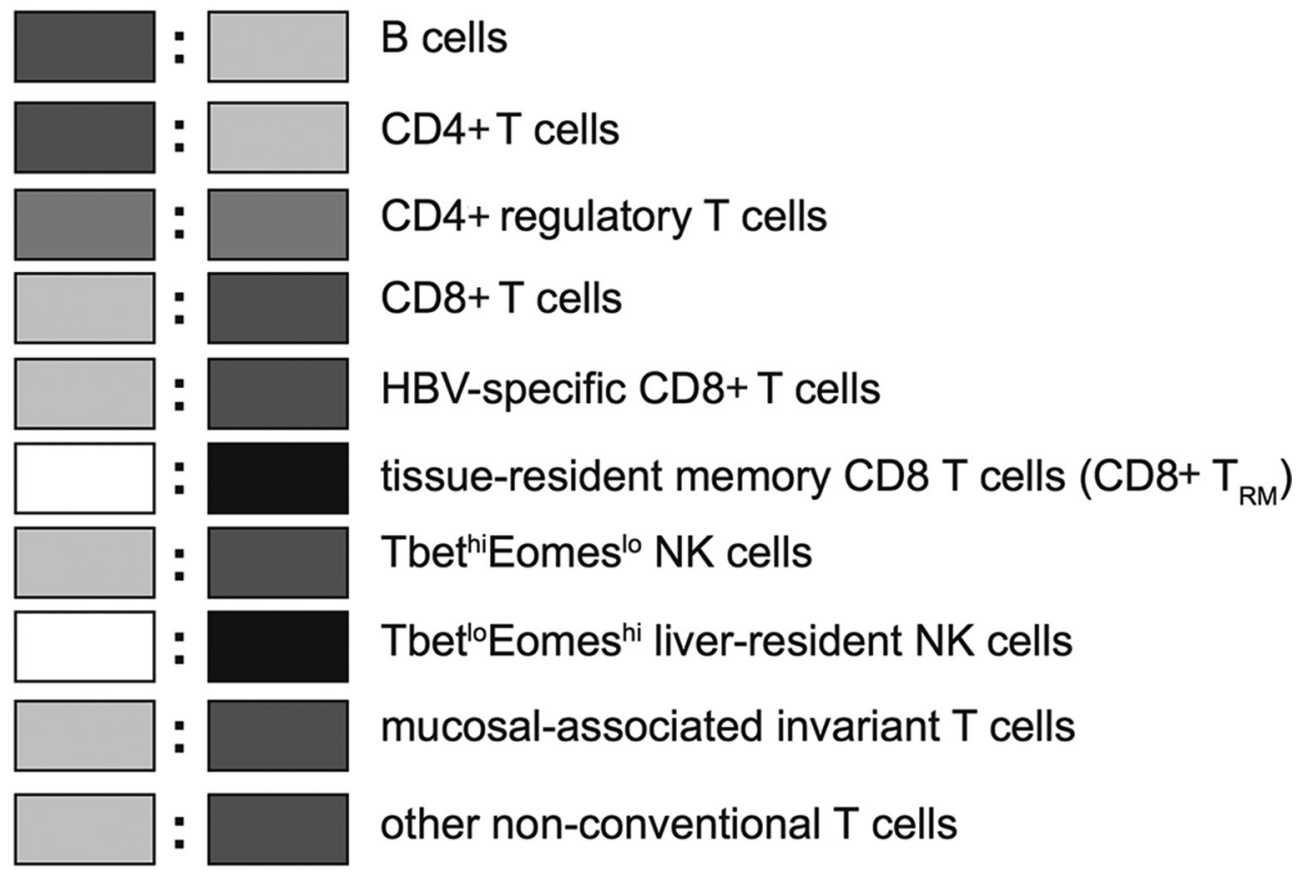

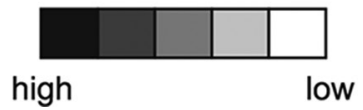

\section{relative frequency between blood \& liver}

Figure 3 Relative frequencies of lymphocyte subsets between the blood and the liver (key indicates relative abundance between the two sites, not between different cell types).

to their T cell receptor (TCR)-dependent recognition of MHC class I-related molecule-presented bacterial riboflavin derivatives, they can be activated in a TCR-independent manner by viral infection or toll-like receptor (TLR)-8 agonists to produce substantial quantities of interferon- $\gamma(\text { IFN- } \gamma)^{71} 72$; as with NK cells, this requires accessory cell production of IL-12/IL-18. ${ }^{73}$ Other non-conventional $\mathrm{T}$ cells enriched within the liver include $\gamma \delta$-T cells. ${ }^{74}$

\section{Immunological compartmentalisation in the liver}

We have characterised a novel population of tissue-resident memory $T$ cells $\left(T_{R M}\right)$ that can persist long term in the human HBV-infected liver and do not recirculate. These CD8 T cells have specialised adaptations for maintaining antiviral surveillance within the tolerogenic liver environment. We find liver-resident CD8 T cells, ${ }^{75-78}$ defined by the coexpression of retention markers CD69 and CD103 and by a unique transcription factor profile (T-bet ${ }^{\text {lo }}$ Eomes ${ }^{\text {lo }}$ Blimp- ${ }^{\text {hi }}{ }$ Hobit ${ }^{\text {lo }}$; figure 2 ), within both healthy and HBV-infected livers but never in the blood. ${ }^{67}$ Importantly, they are selectively increased in patients with well-controlled HBV infection, contain T cells specific for epitopes from all major HBV proteins and survive in the liver even after resolution of infection. All intrahepatic T cells express more PD-1 than those in the circulation but levels of this coinhibitory receptor are significantly higher on CD8 $\mathrm{T}_{\mathrm{RM}}$. Despite this, CD8 $\mathrm{T}_{\mathrm{RM}}$ are able to produce antiviral cytokines rapidly on restimulation, perhaps as a result of their high cell-autonomous IL- $2,{ }^{67}$ which has been shown to overcome PD-1-driven exhaustion. ${ }^{79}$ By contrast, liver CD8 $\mathrm{T}_{\mathrm{RM}}$ have lower granzyme expression than other non-resident intrahepatic CD8 T cells, suggesting they may be adapted to favour non-cytolytic over cytolytic antiviral function in order to preserve organ integrity. ${ }^{6780}$ Thus, a large fraction of HBV-specific T cells are compartmentalised within the liver, restrained by high PD-1 to avoid excessive proliferation and senescence and allow long-term persistence, yet poised for rapid frontline protection. ${ }^{81}$

The presence of a population of memory CD8 $\mathrm{T}$ cells persisting within an organ long after infection resolution, yet retaining immediate antigen-specific effector function, was originally described for a neurotropic influenza virus 20 years ago. ${ }^{82}$ In recent years, the concept of tissue-resident memory $\mathrm{T}$ cells has received a lot more attention, with elegant murine and human studies revealing their very high frequency among memory pools in many organs and their key role in both pathogen protection and disease pathogenesis. ${ }^{83-85}$ Many of the adaptations that we noted in liver $\mathrm{T}_{\mathrm{RM}}$ such as rapid effector function despite inhibitory receptors, and low turnover, are core features shared between human $\mathrm{T}_{\mathrm{RM}}$ in different tissues, ${ }^{86}$ whereas others, such as the capacity to patrol and remain within the sinusoids (through expression of lymphocyte functional-associated antigen-1 and CXCR6), are liver-specialised characteristics. ${ }^{75-778788}$

The finding that a population of HBV-specific CD8 T cells with $T_{R M}$ characteristics can survive within the liver following HBV resolution provides a blueprint for future therapeutic attempts to achieve functional cure. It remains to be seen whether the cytokine signals (sequential IL-15 and TGF- $\beta$ ) that we found could impose the liver-resident signature on peripheral $\mathrm{T}$ cells in vitro, will have therapeutic applicability. ${ }^{67}$ Critically, it will not 
be possible to evaluate whether future novel immunotherapeutic strategies for HBV are harnessing or recapitulating this resident population, as recently described for a malaria vaccine, ${ }^{89}$ unless the liver is sampled. Likewise, it will be difficult to fully understand the constraints that persisting HBV-specific T cells have to operate under, and their range of adaptations, unless those that live exclusively in the liver are studied.

The phenomenon of specialised lymphocyte populations being retained within the liver and not amenable to sampling in the blood is not restricted to CD8 $\mathrm{T}_{\mathrm{RM}}$. Tissue-resident memory CD4 T cells are also well-described in other settings and may well play a role in $\mathrm{CHB}$ and there are likely other subsets of liver-resident cells yet to be defined. Another liver-resident population that has come to light recently is a subset of NK cells expressing high levels of CXCR6,${ }^{90}$ again with a distinctive transcriptional profile: Tbet ${ }^{\text {lo }}$ Eomes $^{\text {hi }}$ (figure 2). ${ }^{91} 92$ Analysis of human liver allografts has suggested that these NK cells can be derived from the circulating NK cell subset, then becoming imprinted by the liver to remain resident for many years. ${ }^{93}$ This population is present in healthy and diseased livers at highly variable frequencies; the factors determining their frequency and physiological roles remain to be determined. In the setting of HBV infection they are able to express the death ligand TRAIL (figure 2), an inducible defence system allowing them to kill hepatocytes, stellate cells and HBV-specific T cells. ${ }^{2126} 6994$ In support of the latter, in situ analysis by immunohistochemistry of HBV sections from liver biopsies allowed the visualisation of NK cells in close proximity to $\mathrm{T}$ cells within the liver sinusoids. ${ }^{26}$ Antiviral and immunotherapeutic strategies used in HBV, particularly those inducing IFN- $\alpha$, can potently expand and activate NK cells, ${ }^{95} 96$ with NAs having limited impact on these cells. ${ }^{96}{ }^{97}$ It will again be informative to sample the liver in order to see whether these and novel therapies differentially modulate liver-resident NK cells and their antiviral and immunoregulatory potential. These targeted analyses of selected immune cells have begun to be complemented by comprehensive approaches, comparing peripheral and intrahepatic transcriptome/proteome profiling to detect additional features of HBV in an unbiased manner. ${ }^{98-100}$

\section{Virological compartmentalisation}

As discussed above, sampling of liver tissue is required for the direct measurement of cccDNA and its transcriptional activity as existing surrogates measured in the circulation have substantial limitations. There are limited data on the impact of therapy on the decay of cccDNA $^{101102}$ and accurate future assessment of novel therapies on cccDNA will still ideally require liver biopsies.

Furthermore, the detection of integrated DNA and its response to novel therapies, an additional therapeutic goal under consideration, also relies on liver sampling. ${ }^{50}$ Integration of HBV DNA occurs through a process of illegitimate recombination by host enzymes acting on double stranded linear DNA, ${ }^{103} 104$ not required for productive replication. Integrated sequences cannot provide an adequate template for productive replication, but can produce HBsAg. Previously, the majority of research regarding integrated HBV DNA focused on its potential to drive hepatocellular carcinoma (HCC), however, recent work has shown that HBV DNA integration appears to occur early during infection and is detectable in patients considered to be in the so-called immune-tolerant disease phase (HBeAg+chronicinfection). ${ }^{50}$ The presence of integrated HBV DNA, its role in clonal hepatocyte expansion and events leading to hepatocarcinogenesis require further investigation, underscoring the need for more studies based on human tissue samples. ${ }^{105}$ Furthermore, the evaluation of current drugs and novel therapies, their impact on HBV DNA integration and the modulation of cancer risk in $\mathrm{CHB}$ will require the study of liver tissue. Until new biomarkers are devised that are capable of identifying patients at risk of HCC development, liver biopsy remains an indispensable tool in the pursuit for HBV cure.

Along with the evaluation of cccDNA and integrated HBV DNA in the infected-liver, the presence, quantification and localisation of $\mathrm{HBV}$ antigens at the site of infection remains vital to further augment our understanding of immunopathogensis, and translation through to HBV therapies. Our previous work has shown the differentiation of disease phase based on $\mathrm{HBcAg}$ localisation, with redistribution from the nucleus to the cytoplasm as liver damage occurs. The mosaic distribution of HBV antigens might reflect different virological/immunological features, which merit further characterisation. ${ }^{50}$ These data are supported by a recent study underlining the link between $\mathrm{HBcAg}$ expression, HBV replication and higher cccDNA content within hepatocytes. ${ }^{106}$ Recent work has indicated that HBV antigens may not be adequately stained using conventional immunohistochemical methods ${ }^{107}$ and further work using liver tissue is required to optimise their detection, using techniques such as in situ hybridisation probes. ${ }^{106}$

\section{A WAY FORWARD}

How can we reconcile the need to sample the liver with the growing tendency to circumvent liver biopsy in the routine management of $\mathrm{CHB}$ ? It is clear that much remains to be learnt about the histological, virological and immunological aspects of this disease that are restricted to the liver itself. This need is particularly pertinent when assessing new therapies or combinations; in order to learn as much as possible about why these may fail and how they can be further refined, it is vital to maximise the information gleaned by including samples from the site of infection and pathology. The new findings of liver-resident populations of $\mathrm{T}$ and NK cells serve to underscore this paradigm. Much more remains to be learnt about adaptations of lymphocytes to the liver environment and their potential for therapeutic manipulation. Similarly, the discovery that HBV antigens and nucleic acids have distinct spatial distribution highlights the value of more sophisticated in situ analysis of virological events at the single cell level using liver sections of patients treated with novel antiviral agents. ${ }^{106}$ Liver biopsies will continue to provide that vital telescope onto the battlefield. On the other hand, it is natural that patients and clinicians favour non-invasive assessments wherever possible.

Perhaps a good compromise for the immediate future will be to ensure that liver biopsies at least continue to be carried out in cases where the risk/benefit ratio is favourable for patients because histological assessment will help to guide clinical management. Examples of this include assessing the need to commence antiviral therapy in $\mathrm{HBeAg}$-negative hepatitis with borderline or discrepant liver enzymes and elastography results or in patients who may have subtle liver disease despite fulfilling classical serum criteria of 'immune tolerance'. ${ }^{108}$ Many clinicians consider that a biopsy is still justifiable to assess disease stage in the majority of patients with $\mathrm{CHB}$. Since it has been shown that multiple passes do not increase the risk of complications, ${ }^{109}$ it makes sense to ensure that sufficient tissue is obtained to allow thorough histological assessment, and state-of-the-art assays for compartmentalised viral and immunological parameters such as cccDNA and HBV-specific T cells. In some cases, flow cytometric analysis could be supplemented by unbiased techniques such as RNA-sequencing (RNA-Seq) and 
proteomics/metabolomics to learn more about the liver milieu as well as its cellular constituents.

A setting where there is a particularly strong argument to sample the liver is in early phase clinical trials of novel therapies for $\mathrm{CHB}$, in order to optimally define their mechanism of action and limitations. It is crucial to assess the impact of antiviral and immunomodulatory approaches on end points such as cccDNA and integrated DNA within the liver as well as proxy measures like HBV DNA and HBsAg in the periphery. If, for example, a therapeutic vaccine or checkpoint inhibitor does not achieve functional cure, it will be informative to see whether it failed to expand liver-resident HBV-specific T cells. Such assessments ideally require paired pretreatment and end-of-treatment biopsies, which may continue to be achievable in substudies with limited patient numbers. However, it must be acknowledged that the mainstay of clinical and immune monitoring of $\mathrm{CHB}$ trials will continue to be peripheral blood. With evolving advances in high dimensional analysis of peripheral blood mononuclear cells (PBMC), it should ultimately be possible to identify fingerprints within the peripheral immune response that can be used as indirect biomarkers of treatment efficacy within an organ. This approach was exemplified by a recent study predicting tumour responses to PD-1 blockade using bloodbased immune profiling combined with tumour imaging. ${ }^{110} \mathrm{~A}$ period of consolidated effort to sample blood and liver in parallel is therefore essential to delineate peripheral markers that adequately reflect intrahepatic events in CHB. Historical data from studies in chimpanzees and woodchucks where both blood and liver were sampled should also be mined to learn more about the relationship between peripheral and intrahepatic changes. ${ }^{111} 112$

Another solution to facilitate longitudinal assessment of novel therapies is the use of fine-needle aspirates (FNA) of the liver in place of biopsies. This technique was first shown to allow monitoring of immune parameters of CHB in $2005,{ }^{113}$ but has not yet been widely adopted. It can also allow some limited assessment of hepatocytes and intrahepatic HBV antigens. ${ }^{114}$ Because it is rapid, painless and very safe, it can be repeated within as short an interval as 6 hours, and allows serial sampling through the course of therapy, as described recently in patients with HCV. ${ }^{115116}$ At least 100000 cells can be obtained, which allows several immune subsets to be examined using multiparameter flow and high dimensional analysis or even single cell PCR on sorted populations. ${ }^{117118}$ We are currently investigating whether the full complement of liver-resident lymphocytes seen in tissue biopsies can also be extracted by FNA.

While FNA may prove very useful for selective immune-monitoring of $\mathrm{CHB}$ treatment trials, it does not allow histological staining to examine responses in situ and better elucidate HBV pathogenesis. For this, better use could be made of stored paraffin-embedded sections from the era when liver biopsies were more common in CHB. New multiplexed immunostaining, allowing automated quantitative assessment of multiple proteins on a single slide, will open up the opportunity for much more comprehensive visualisation of the topography of HBV viral particles and antigens in combination with immune infiltrates. This is vital in order to image the spatial relationship between infected hepatocytes and immune cells to better illuminate hostpathogen interactions. At present, even the proportion and distribution of infected hepatocytes and their relationship to immune infiltrates has not been defined for different phases of infection. In addition to staining for $\mathrm{HBsAg}$ and $\mathrm{HBcAg}$, it is now possible to use highly sensitive probes for in site hybridisation of HBV RNA. ${ }^{119}$ Other mechanisms to enhance our knowledge of the liver-specific environment in $\mathrm{CHB}$ include the capacity to now culture and infect primary human hepatocytes and to use three-dimensional models recapitulating some of their interactions with, for example, Kupffer cells or stellate cells along with the addition of immune cells. ${ }^{120-122}$

In summary, a wave of new agents to treat HBV will be reaching clinical trials in the next few years. In order to capitalise on the opportunity to learn from these initial attempts at functional cure, and to select optimal combinations, it is imperative that we intensify efforts to sample the liver as well as blood. This need has been reinforced by recent studies highlighting unique immune responses compartmentalised within the liver, along with the hallmarks of persistent HBV: integrated and cccDNA. Available liver tissue or aspirates must be used in carefully planned virological and immunological studies, aided by new techniques that allow simultaneous assessment of many parameters. Studies including liver samples will provide vital clues to modify and combine the array of new antiviral and immunomodulatory therapies on the horizon for HBV.

Funding The authors were supported by a Medical Research Council grant (G0801213) and a Wellcome Trust Senior Investigator Award and Enhancement (101849/Z/13/A) to MKM. Wellcome Trust Clinical Research Training Fellowship (107389/Z/15/Z) awarded to USG. A Barts and The London Charity Project Grant (723/1795) and an NIHR Research for patient benefit award (PB-PG-0614-34087) to PTFK.

Competing interests USG has no conflicts of interest to declare; LIP has participated in a Gilead advisory board; PTFK has collaborative grant funding from Gilead, participates in advisory board/provides consultancy to Gilead, Janssen and is an investigator for industry-led trials with Gilead, Janssen, Alere, Assembly Biosciences. MKM's laboratory has collaborative grant funding from Gilead and Roche; MKM participates in advisory boards/provides consultancy to Gilead, Roche, Arbutus Biopharma, Immunocore.

Provenance and peer review Not commissioned; externally peer reviewed.

Open Access This is an Open Access article distributed in accordance with the terms of the Creative Commons Attribution (CC BY 4.0) license, which permits others to distribute, remix, adapt and build upon this work, for commercial use, provided the original work is properly cited. See: http://creativecommons.org/licenses/by/4.0/

(c) Article author(s) (or their employer(s) unless otherwise stated in the text of the article) 2018. All rights reserved. No commercial use is permitted unless otherwise expressly granted.

\section{REFERENCES}

1 Stanaway JD, Flaxman AD, Naghavi M, et al. The global burden of viral hepatitis from 1990 to 2013: findings from the Global Burden of Disease Study 2013. Lancet 2016;388:1081-8

2 Durantel D, Zoulim F. New antiviral targets for innovative treatment concepts for hepatitis B virus and hepatitis delta virus. J Hepatol 2016;64(1 Suppl):S117-S131.

3 Gill US, Kennedy PTF. Current therapeutic approaches for HBV infected patients. J Hepatol 2017:67:412-4.

4 Singh S, Muir AJ, Dieterich DT, et al. American Gastroenterological Association Institute Technical Review on the Role of Elastography in Chronic Liver Diseases. Gastroenterology 2017:152:1544-77.

5 Parikh P, Ryan JD, Tsochatzis EA. Fibrosis assessment in patients with chronic hepatitis B virus (HBV) infection. Ann Trans/ Med 2017;5:40.

6 Kennedy PT, Lee HC, Jeyalingam L, et al. NICE guidelines and a treatment algorithm for the management of chronic hepatitis $\mathrm{B}$ : a review of 12 years experience in west London. Antivir Ther 2008:13:1067-76.

7 Sarri G, Westby M, Bermingham S, et al. Diagnosis and management of chronic hepatitis B in children, young people, and adults: summary of NICE guidance. BMJ 2013;346:f3893.

8 European Association For The Study Of The Liver. [EASL clinical practice guidelines. Management of chronic hepatitis B]. Gastroenterol Clin Biol 2009;33:539-54.

9 European Association For The Study Of The Liver. EASL clinical practice guidelines: Management of chronic hepatitis B virus infection. J Hepatol 2012;57:167-85.

10 European Association for the Study of the Liver. Electronic address eee, European Association for the Study of the L. EASL 2017 Clinical Practice Guidelines on the management of hepatitis B virus infection. J Hepatol 2017.

11 Lok AS. McMahon BJ: Chronic hepatitis B. Hepatology 2007;45:507-39.

12 Lok AS. McMahon BJ: Chronic hepatitis B: update 2009. Hepatology 2009;50:661-2.

13 Terrault NA, Bzowej NH, Chang KM, et al. American Association for the Study of Liver D: AASLD guidelines for treatment of chronic hepatitis B. Hepatology 2016;63:261-83 
14 Benedito J, Carcel J, Clemente G, et al. Cheese maturity assessment using ultrasonics. J Dairy Sci 2000;83:248-54.

15 Parkes J, Roderick P, Harris S, et al. Enhanced liver fibrosis test can predict clinical outcomes in patients with chronic liver disease. Gut 2010;59:1245-51.

16 Trembling PM, Lampertico P, Parkes J, et al. Performance of Enhanced Liver Fibrosis test and comparison with transient elastography in the identification of liver fibrosis in patients with chronic hepatitis B infection. J Viral Hepat 2014:21:430-8.

17 Tsochatzis EA, Gurusamy KS, Ntaoula S, et al. Elastography for the diagnosis of severity of fibrosis in chronic liver disease: a meta-analysis of diagnostic accuracy. J Hepatol 2011;54:650-9.

18 Wong GL, Wong VW, Chim AM, et al. Factors associated with unreliable liver stiffness measurement and its failure with transient elastography in the Chinese population. J Gastroenterol Hepatol 2011;26:300-5.

19 Maini MK, Boni C, Lee CK, et al. The role of virus-specific CD8(+) cells in liver damage and viral control during persistent hepatitis B virus infection. J Exp Med 2000;191:1269-80.

20 Webster GJ, Reignat S, Brown D, et al. Longitudinal analysis of CD8+ T cells specific for structural and nonstructural hepatitis $B$ virus proteins in patients with chronic hepatitis B: implications for immunotherapy. J Virol 2004:78:5707-19.

21 Dunn C, Brunetto M, Reynolds G, et al. Cytokines induced during chronic hepatitis $B$ virus infection promote a pathway for NK cell-mediated liver damage. J Exp Med 2007:204:667-80.

22 Chang JJ, Thompson AJ, Visvanathan K, et al. The phenotype of hepatitis B virusspecific T cells differ in the liver and blood in chronic hepatitis B virus infection. Hepatology 2007;46:1332-40.

23 Das A, Hoare M, Davies N, et al. Functional skewing of the global CD8 T cell population in chronic hepatitis B virus infection. J Exp Med 2008;205:2111-24.

24 Fisicaro P, Valdatta C, Massari M, et al. Antiviral intrahepatic T-cell responses can be restored by blocking programmed death-1 pathway in chronic hepatitis $B$. Gastroenterology 2010;138:682-93.

25 Raziorrouh B, Schraut W, Gerlach T, et al. The immunoregulatory role of CD244 in chronic hepatitis B infection and its inhibitory potential on virus-specific CD8+ T-cell function. Hepatology 2010;52:1934-47.

26 Peppa D, Gill US, Reynolds G, et al. Up-regulation of a death receptor renders antiviral T cells susceptible to NK cell-mediated deletion. J Exp Med 2013;210:99-114.

27 Bengsch B, Martin B, Thimme R. Restoration of HBV-specific CD8+ T cell function by PD-1 blockade in inactive carrier patients is linked to T cell differentiation. J Hepatol 2014:61:1212-9.

28 Boni C, Fisicaro P, Valdatta C, et al. Characterization of hepatitis B virus (HBV)specific T-cell dysfunction in chronic HBV infection. J Virol 2007;81:4215-25.

29 Huang WC, Easom NJ, Tang XZ, et al. T Cells Infiltrating Diseased Liver Express Ligands for the NKG2D Stress Surveillance System. J Immunol 2017;198:1172-82.

30 Pallett LJ, Gill US, Quaglia A, et al. Metabolic regulation of hepatitis B immunopathology by myeloid-derived suppressor cells. Nat Med 2015;21:591-600.

31 Das A, Ellis G, Pallant C, et al. IL-10-producing regulatory B cells in the pathogenesis of chronic hepatitis B virus infection. J Immunol 2012;189:3925-35.

32 Farci P, Diaz G, Chen Z, et al. B cell gene signature with massive intrahepatic production of antibodies to hepatitis B core antigen in hepatitis $B$ virus-associated acute liver failure. Proc Natl Acad Sci U S A 2010;107:8766-71.

33 Zoulim F. New insight on hepatitis B virus persistence from the study of intrahepatic viral cccDNA. J Hepatol 2005;42:302-8

34 Liang TJ, Block TM, McMahon BJ, et al. Present and future therapies of hepatitis B: From discovery to cure. Hepatology 2015;62:1893-908.

35 Chan HL, Wong VW, Tse AM, et al. Serum hepatitis B surface antigen quantitation can reflect hepatitis $B$ virus in the liver and predict treatment response. Clin Gastroenterol Hepatol 2007;5:1462-8.

36 Thompson AJ, Nguyen T, Iser D, et al. Serum hepatitis B surface antigen and hepatitis B e antigen titers: disease phase influences correlation with viral load and intrahepatic hepatitis B virus markers. Hepatology 2010;51:1933-44.

37 Kumar R, Pérez-Del-Pulgar S, Testoni B, et al. Clinical relevance of the study of hepatitis B virus covalently closed circular DNA. Liver Int 2016;36 Suppl 1:72-7.

38 Wooddell $\mathrm{Cl}$, Yuen MF, Chan HL, et al. RNAi-based treatment of chronically infected patients and chimpanzees reveals that integrated hepatitis $B$ virus DNA is a source of HBsAg. Sci Transl Med 2017;9:eaan0241.

39 Block TM, Locarnini S, McMahon BJ, et al. Use of Current and New Endpoints in the Evaluation of Experimental Hepatitis B Therapeutics. Clin Infect Dis 2017;64:1283-8.

40 Chan HL, Thompson A, Martinot-Peignoux M, et al. Hepatitis B surface antigen quantification: why and how to use it in 2011 - a core group report. J Hepatol 2011;55:1121-31.

41 Pollicino T, Amaddeo G, Restuccia A, et al. Impact of hepatitis B virus (HBV) preS/S genomic variability on HBV surface antigen and HBV DNA serum levels. Hepatology 2012;56:434-43.

42 Seto WK, Wong DK, Fung J, et al. Linearized hepatitis B surface antigen and hepatitis $B$ core-related antigen in the natural history of chronic hepatitis B. Clin Microbiol Infect 2014;20:1173-80.
43 Suzuki F, Miyakoshi H, Kobayashi M, et al. Correlation between serum hepatitis B virus core-related antigen and intrahepatic covalently closed circular DNA in chronic hepatitis B patients. J Med Virol 2009;81:27-33.

44 Chen EQ, Feng S, Wang ML, et al. Serum hepatitis B core-related antigen is a satisfactory surrogate marker of intrahepatic covalently closed circular DNA in chronic hepatitis B. Sci Rep 2017;7:173.

45 Su Q, Wang SF, Chang TE, et al. Circulating hepatitis B virus nucleic acids in chronic infection : representation of differently polyadenylated viral transcripts during progression to nonreplicative stages. Clin Cancer Res 2001;7:2005-15

46 van Bömmel F, Bartens A, Mysickova A, et al. Serum hepatitis B virus RNA levels as an early predictor of hepatitis $B$ envelope antigen seroconversion during treatment with polymerase inhibitors. Hepatology 2015;61:66-76.

47 Wang J, Shen T, Huang $X$, et al. Serum hepatitis B virus RNA is encapsidated pregenome RNA that may be associated with persistence of viral infection and rebound. J Hepatol 2016:65:700-10.

48 Nguyen LH, Chao D, Lim JK, et al. Histologic changes in liver tissue from patients with chronic hepatitis $B$ and minimal increases in levels of alanine aminotransferase: a meta-analysis and systematic review. Clin Gastroenterol Hepatol 2014;12:1262-6.

49 Ormeci A, Aydın Y, Sumnu A, et al. Predictors of treatment requirement in $\mathrm{HBeAg-negative} \mathrm{chronic} \mathrm{hepatitis} \mathrm{B} \mathrm{patients} \mathrm{with} \mathrm{persistently} \mathrm{normal} \mathrm{alanine}$ aminotransferase and high serum HBV DNA levels. Int J Infect Dis 2016;52:68-73.

50 Mason WS, Gill US, Litwin S, et al. HBV DNA Integration and Clonal Hepatocyte Expansion in Chronic Hepatitis B Patients Considered Immune Tolerant. Gastroenterology 2016;151:986-98

51 Mannan R, Misra V, Misra SP, et al. A comparative evaluation of scoring systems for assessing necro-inflammatory activity and fibrosis in liver biopsies of patients with chronic viral hepatitis. J Clin Diagn Res 2014;8:FC08-12.

52 Tsochatzis E, Bruno S, Isgro G, et al. Collagen proportionate area is superior to other histological methods for sub-classifying cirrhosis and determining prognosis. J Hepatol 2014;60:948-54.

53 Torres R, Vesuna S, Levene MJ. High-resolution, 2- and 3-dimensional imaging of uncut, unembedded tissue biopsy samples. Arch Pathol Lab Med 2014; 138:395-402.

54 Mani H, Kleiner DE. Liver biopsy findings in chronic hepatitis B. Hepatology 2009:49:S61-S71.

55 Theise ND. Liver biopsy assessment in chronic viral hepatitis: a personal, practical approach. Mod Pathol 2007;20 Suppl 1(Suppl 1):S3-S14.

56 Zhang JY, Zhang Z, Lin F, et al. Interleukin-17-producing CD4(+) T cells increase with severity of liver damage in patients with chronic hepatitis B. Hepatology 2010;51:81-91

57 Bonorino P, Ramzan M, Camous X, et al. Fine characterization of intrahepatic NK cells expressing natural killer receptors in chronic hepatitis B and C. J Hepatol 2009;51:458-67.

58 Protzer U, Maini MK, Knolle PA. Living in the liver: hepatic infections. Nat Rev Immunol 2012;12:201-13.

59 Crispe IN. The liver as a lymphoid organ. Annu Rev Immunol 2009:27:147-63.

60 Maini MK, Gehring AJ. The role of innate immunity in the immunopathology and treatment of HBV infection. J Hepatol 2016;64(1 Suppl):S60-S70.

61 Heymann F, Peusquens J, Ludwig-Portugall I, et al. Liver inflammation abrogates immunological tolerance induced by Kupffer cells. Hepatology 2015;62:279-91.

$62 \mathrm{Xu} \mathrm{D}, \mathrm{Fu} J$, Jin L, et al. Circulating and liver resident CD4+CD25+ regulatory T cells actively influence the antiviral immune response and disease progression in patients with hepatitis B. J Immunol 2006:177:739-47.

63 Zhang M, Zhou J, Zhao T, et al. Dissection of a circulating and intrahepatic CD4(+) Foxp3(+) T-cell subpopulation in chronic hepatitis B virus (HBV) infection: a highly informative strategy for distinguishing chronic HBV infection states. J Infect Dis 2012:205:1111-20.

64 Yang G, Liu A, Xie Q, et al. Association of CD4+CD25+Foxp3+ regulatory T cells with chronic activity and viral clearance in patients with hepatitis B. Int Immunol 2007;19:133-40

65 Manigold T, Racanelli V. T-cell regulation by CD4 regulatory T cells during hepatitis B and C virus infections: facts and controversies. Lancet Infect Dis 2007;7:804-13.

66 Stoop JN, Claassen MA, Woltman AM, et al. Intrahepatic regulatory T cells are phenotypically distinct from their peripheral counterparts in chronic HBV patients. Clin Immunol 2008;129:419-27.

67 Pallett LJ, Davies J, Colbeck EJ, et al. IL-2high tissue-resident T cells in the human liver: Sentinels for hepatotropic infection. J Exp Med 2017;214:1567-80.

68 Björkström NK, Ljunggren HG, Michaëlsson J. Emerging insights into natural killer cells in human peripheral tissues. Nat Rev Immunol 2016;16:310-20.

69 Peppa D, Micco L, Javaid A, et al. Blockade of immunosuppressive cytokines restores NK cell antiviral function in chronic hepatitis B virus infection. PLOS Pathog 2010:6:e1001227.

70 Kurioka A, Walker LJ, Klenerman P, et al. MAIT cells: new guardians of the liver. Clin Trans/ Immunology 2016;5:e98.

71 Jo J, Tan AT, Ussher JE, et al. Toll-like receptor 8 agonist and bacteria trigger potent activation of innate immune cells in human liver. PLoS Pathog 2014;10:e1004210.

72 van Wilgenburg B, Scherwitzl I, Hutchinson EC, et al. MAIT cells are activated during human viral infections. Nat Commun 2016;7:11653. 
73 Zhang Z, Zhang S, Zou Z, et al. Hypercytolytic activity of hepatic natural killer cells correlates with liver injury in chronic hepatitis B patients. Hepatology 2011;53:73-85.

74 Gao B, Jeong WI, Tian Z. Liver: An organ with predominant innate immunity. Hepatology 2008:47:729-36.

75 Steinert EM, Schenkel JM, Fraser KA, et al. Quantifying Memory CD8 T Cells Reveals Regionalization of Immunosurveillance. Cell 2015;161:737-49.

76 McNamara HA, Cai Y, Wagle MV, et al. Up-regulation of LFA-1 allows liverresident memory $T$ cells to patrol and remain in the hepatic sinusoids. Sci Immunol 2017;2:eaaj1996.

77 Fernandez-Ruiz D, Ng WY, Holz LE, et al. Liver-Resident Memory CD8+ T Cells Form a Front-Line Defense against Malaria Liver-Stage Infection. Immunity 2016:45:889-902.

78 Wong MT, Ong DE, Lim FS, et al. A high-dimensional atlas of human T cell diversity reveals tissue-specific trafficking and cytokine signatures. Immunity 2016;45:442-56.

79 Schurich A, Berg M, Stabenow D, et al. Dynamic regulation of CD8 T cell tolerance induction by liver sinusoidal endothelial cells. J Immunol 2010;184:4107-14.

80 Stelma F, de Niet A, Sinnige MJ, et al. Human intrahepatic CD69 + CD8+ T cells have a tissue resident memory $T$ cell phenotype with reduced cytolytic capacity. Sci Rep 2017:7:6172.

81 Bolte FJ, Rehermann B. Tissue-resident T cells in hepatitis B: A new target for cure? J Exp Med 2017;214:1564-6.

82 Hawke S, Stevenson PG, Freeman S, et al. Long-term persistence of activated cytotoxic T lymphocytes after viral infection of the central nervous system. J Exp Med 1998;187:1575-82.

83 Sathaliyawala T, Kubota M, Yudanin N, et al. Distribution and compartmentalization of human circulating and tissue-resident memory T cell subsets. Immunity 2013;38:187-97.

84 Mueller SN, Mackay LK. Tissue-resident memory T cells: local specialists in immune defence. Nat Rev Immunol 2016;16:79-89.

85 Park CO, Kupper TS. The emerging role of resident memory T cells in protective immunity and inflammatory disease. Nat Med 2015;21:688-97.

86 Kumar BV, Ma W, Miron M, et al. Human tissue-resident memory T cells are defined by core transcriptional and functional signatures in lymphoid and mucosal sites. Cell Rep 2017;20:2921-34.

87 Tse SW, Radtke AJ, Espinosa DA, et al. The chemokine receptor CXCR6 is required for the maintenance of liver memory CD8(+) T cells specific for infectious pathogens. $J$ Infect Dis 2014;210:1508-16.

88 Guidotti LG, Inverso D, Sironi L, et al. Immunosurveillance of the liver by intravascular effector CD8(+) T cells. Cell 2015;161:486-500.

89 Ishizuka AS, Lyke KE, DeZure A, et al. Protection against malaria at 1 year and immune correlates following PfSPZ vaccination. Nat Med 2016;22:614-23.

90 Hudspeth K, Donadon M, Cimino M, et al. Human liver-resident CD56(bright)/ CD16(neg) NK cells are retained within hepatic sinusoids via the engagement of CCR5 and CXCR6 pathways. J Autoimmun 2016;66:40-50.

91 Stegmann KA, Robertson F, Hansi N, et al. CXCR6 marks a novel subset of T-bet(lo) Eomes(hi) natural killer cells residing in human liver. Sci Rep 2016;6:26157.

92 Harmon C, Robinson MW, Fahey R, et al. Tissue-resident Eomes(hi) T-bet(lo) CD56(bright) NK cells with reduced proinflammatory potential are enriched in the adult human liver. Eur J Immunol 2016:46:2111-20.

93 Cuff AO, Robertson FP, Stegmann KA, et al. Eomeshi NK cells in human liver are long-lived and do not Recirculate but can be replenished from the circulation. J Immunol 2016;197:4283-91.

94 Glässner A, Eisenhardt M, Krämer B, et al. NK cells from HCV-infected patients effectively induce apoptosis of activated primary human hepatic stellate cells in a TRAIL-, FasL- and NKG2D-dependent manner. Lab Invest 2012;92:967-77.

95 Micco L, Peppa D, Loggi E, et al. Differential boosting of innate and adaptive antiviral responses during pegylated-interferon-alpha therapy of chronic hepatitis $B$. J Hepatol 2013;58:225-33.

96 Gill US, Peppa D, Micco L, et al. Interferon alpha induces Sustained changes in NK cell responsiveness to hepatitis B viral load suppression in vivo. PLoS Pathog 2016;12:e1005788

97 Tjwa ET, Zoutendijk R, van Oord GW, et al. Similar frequencies, phenotype and activation status of intrahepatic NK cells in chronic HBV patients after long-term treatment with tenofovir disoproxil fumarate (TDF). Antiviral Res 2016;132:70-5.
$98 \mathrm{Wu} \mathrm{HL}, \mathrm{Hsiao} \mathrm{TH}$, Chen PJ, et al. Liver gene expression profiles correlate with virus infection and response to interferon therapy in chronic hepatitis B patients. Sci Rep 2016;6:31349.

99 Lebossé F, Testoni B, Fresquet J, et al. Intrahepatic innate immune response pathways are downregulated in untreated chronic hepatitis B. J Hepatol 2017;66:897-909.

100 Hou J, Brouwer WP, Kreefft K, et al. Unique intrahepatic transcriptomics profiles discriminate the clinical phases of a chronic HBV infection. PLOS One 2017; 12:e0179920.

101 Boyd A, Lacombe K, Lavocat F, et al. Decay of ccc-DNA marks persistence of intrahepatic viral DNA synthesis under tenofovir in HIV-HBV co-infected patients. J Hepatol 2016;65:683-91.

102 Lai CL, Wong D, Ip P, et al. Reduction of covalently closed circular DNA with long-term nucleos(t)ide analogue treatment in chronic hepatitis B. J Hepatol 2017:66:275-81

103 Yang W, Summers J. Illegitimate replication of linear hepadnavirus DNA through nonhomologous recombination. J Virol 1995;69:4029-36.

104 Bill CA, Summers J. Genomic DNA double-strand breaks are targets for hepadnaviral DNA integration. Proc Natl Acad Sci U S A 2004;101:11135-40.

105 Tu T, Budzinska MA, Shackel NA, et al. HBV DNA integration: molecular mechanisms and clinical implications. Viruses 2017;9:75.

106 Zhang X, Lu W, Zheng Y, et al. In situ analysis of intrahepatic virological events in chronic hepatitis B virus infection. J Clin Invest 2016;126:1079-92.

107 Luckenbaugh L, Kitrinos KM, Delaney WE, et al. Genome-free hepatitis B virion levels in patient sera as a potential marker to monitor response to antiviral therapy. J Viral Hepat 2015;22:561-70.

108 Kennedy PTF, Sandalova E, Jo J, et al. Preserved T-cell function in children and young adults with immune-tolerant chronic hepatitis B. Gastroenterology 2012;143:637-45.

109 Chi H, Hansen BE, Tang WY, et al. Multiple biopsy passes and the risk of complications of percutaneous liver biopsy. Eur J Gastroenterol Hepatol 2017:29:36-41.

110 Huang AC, Postow MA, Orlowski RJ, et al. T-cell invigoration to tumour burden ratio associated with anti-PD-1 response. Nature 2017;545:60-5.

111 Fletcher SP, Chin DJ, Gruenbaum L, et al. Intrahepatic transcriptional signature associated with response to interferon- $\alpha$ treatment in the woodchuck model of chronic hepatitis B. PLoS Pathog 2015;11:e1005103.

112 Glebe D, Lorenz H, Gerlich WH, et al. Correlation of virus and host response markers with circulating immune complexes during acute and chronic woodchuck hepatitis virus infection. J Virol 2009;83:1579-91.

113 Sprengers D, van der Molen RG, Kusters JG, et al. Flow cytometry of fine-needleaspiration biopsies: a new method to monitor the intrahepatic immunological environment in chronic viral hepatitis. J Viral Hepat 2005;12:507-12.

114 van der Laan LJ, Taimr P, Kok A, et al. Flowcytometric quantitation of hepatitis B viral antigens in hepatocytes from regular and fine-needle biopsies. J Virol Methods 2007:142:189-97.

115 Pembroke T, Christian A, Jones E, et al. The paradox of NKp46+ natural killer cells: drivers of severe hepatitis $C$ virus-induced pathology but in-vivo resistance to interferon $\alpha$ treatment. Gut 2014;63:515-24.

116 Spaan $\mathrm{M}$, van Oord GW, Janssen $\mathrm{HL}$, et al. Longitudinal analysis of peripheral and intrahepatic NK cells in chronic HCV patients during antiviral therapy. Antiviral Res 2015;123:86-92.

117 Pembroke T, Gallimore A, Godkin A. Tracking the kinetics of intrahepatic immune responses by repeated fine needle aspiration of the liver. $J$ Immunol Methods 2015:424:131-5.

118 Hengst J, Theorell J, Deterding K, et al. High-resolution determination of human immune cell signatures from fine-needle liver aspirates. Eur J Immunol 2015;45:2154-7

119 Calabrese D, Wieland SF. Highly sensitive detection of HBV RNA in liver tissue by in situ Hybridization. Methods Mol Biol 2017;1540:119-34.

120 Ong LJY, Chong LH, Jin L, et al. A pump-free microfluidic 3D perfusion platform for the efficient differentiation of human hepatocyte-like cells. Biotechnol Bioeng 2017;114.

121 Pavesi A, Tan AT, Koh S, et al. A 3D microfluidic model for preclinical evaluation of TCR-engineered T cells against solid tumors. JCI Insight 2017;2:2.

122 Winer BY, Huang TS, Pludwinski E, et al. Long-term hepatitis B infection in a scalable hepatic co-culture system. Nat Commun 2017;8:125. 